\title{
The significance of healthy aging for older persons who participated in health education groups
}

\section{Abstract}

Introduction: Different terms have been used to describe the aging process while avoiding the negative consequences of advanced age. In this context healthy aging assumes a more extensive meaning than the absence of disease, and includes a process of adapting to the changes that occur throughout life, related to the maintenance of a healthy old age. Objective: To describe the meaning of healthy aging for older adults who participated in health education groups in the Basic Health Care Service of Porto Alegre in the state of Rio Grande do Sul. Method: A qualitative and descriptive study of older adults who participated in health education groups was performed. The 30 participants answered the question "What is healthy aging for you?" Answers were analyzed using thematic analysis. Results: Twelve categories emerged during analysis, the most frequent of which were: adopt healthy behavior, have a social and support network, keep active, be healthy, be independent and autonomous, and have positive feelings. Conclusion: Wider meanings of healthy aging were identified, which embrace issues relevant to elderly health, although more individual aspects have been described in relation to aging.
Key words: Elderly; Health of the Elderly; Qualitative Research.

Prefeitura Municipal de Cachoeirinha, Secretaria Municipal da Saúde, Departamento de Atenção Básica, Estratégia de Saúde da Família Vereador José Ramos. Cachoeirinha, RS, Brasil.

2 Universidade Federal do Rio Grande do Sul, Escola de Enfermagem, Programa de Pós-graduação em Enfermagem. Porto Alegre, RS, Brasil.

3 Universidade Regional Integrada do Alto Uruguai e das Missões, Departamento de Ciências da Saúde, Curso de Enfermagem. Frederico Westphalen, RS, Brasil. 


\section{INTRODUCTION}

Population aging has led to greater analysis of the lives of the elderly during this phase of life and what can be done to promote greater longevity and dignity, as well as a better quality of life, for this age group. Around the world, particularly in developing countries, tests are needed to help the elderly population stay healthy and active for as long as possible. ${ }^{1}$

Currently, different terms are used to describe an aging process where the negative consequences of advancing age are delayed. These terms include successful aging, healthy aging and, more recently, active aging, a term proposed by the World Health Organization (WHO). ${ }^{1-4}$

A combination of active involvement in life, through the establishment of social relationships and productive activities, the absence of disease and the maintenance of functional capacity broadly represent the concept of successful aging. ${ }^{2}$

The concept of healthy aging goes beyond the mere absence of disease. It is considered to be a process of adaptation to the changes that occur throughout an individual's life, which allows elderly individuals to maintain their physical, mental and social wellbeing. The term healthy aging is strongly associated with the maintenance of a satisfactory old age and the identification of its determinants. ${ }^{3-5}$

At the end of the 1990s, the World Health Organization (WHO) adopted the term "active aging", conceived as a process that seeks to optimize continuous opportunities related to health, safety and participation, so that the quality of life of elderly individuals improves over time. In this context, "active" refers to the physical capacity of elderly individuals in relation to the workforce, as well as their continuous participation in society, including political issues and other issues related to life in the community. ${ }^{1}$

The present study investigated the meaning of healthy aging for elderly people who participated in health education groups in a Basic Health Unit in the Brazilian city of Porto Alegre, in the state of Rio Grande do Sul. These groups encourage habits for the prevention of disease and the improvement of health, tackle issues suggested by the group members, and aim to strengthen social networks between the elderly participants and health professionals. The authors of the present study agree with the authors of several previous studies, who stated that the elderly population is best placed to define healthy aging, as they experience the effects of the aging process on a daily basis. ${ }^{3}$

It has been found that health education groups favor the development of healthy behavior, encourage autonomy among the elderly, improve self-esteem, promote a better quality of life and encourage social inclusion for all participants. They also contribute to the creation of an environment of familiarity and reflection, focusing on the needs of members. ${ }^{6,7}$ A study of elderly individuals who participated in such groups confirmed that they used this environment to share their worries, sadness, love, happiness, affection and knowledge, thereby reducing feelings of fear, insecurity and depression, particularly when faced with the loss of loved ones and family members. ${ }^{6}$ In addition, these factors can influence the continuity of the elderly individuals in programs and positive changes that occur in their lives. ${ }^{8}$

The present study is part of a larger project, titled "Healthy aging in the South of Brazil: facing challenges and developing opportunities for health professionals and the elderly", which was developed jointly by the Universidade Federal do Rio Grande do Sul (UFRGS) and the Centro de Saúde (CS) IAPI da Secretaria Municipal de Saúde ("the Institute for Retirees and Pensioners of Industry Health Center of the Municipal Health Department"). One of the sub-projects is centered on health literacy in the elderly population. In this qualitative sub-project, the researchers adapted and applied an instrument used in a Canadian study, based on the following open question: "What does healthy aging mean to you?" " 9 The answers collected from the elderly participants in the groups are analyzed herein. 
The health education groups in which these elderly individuals participate were selected for the present study as they questioned their members about the aging process, while encouraging social familiarity among the group. In addition, they were not solely focused on the pathologies that are common during this period of life.

A number of previous studies have investigated the perceptions of the elderly in relation to successful aging, active aging and health descriptions. However, very few studies have used the theme of "healthy aging". 10-15 The present study set out to investigate this theme from the perspective of elderly individuals who participated in a care module focused on health promotion and illness prevention. The authors sought to discover if elderly individuals who are already engaged in health education groups run by a basic healthcare service would attribute a different meaning to healthy aging.

The present study will be beneficial to nursing and other health-related professions, given that an understanding of what healthy aging means to the elderly individuals that participate in health education groups can provide professionals with more support during interventions. It can also help to identify the conditions considered determinants for healthy aging among this population and the planning of healthcare that is provided for them when required.

Therefore, the aim of the present study was to describe what healthy aging means to elderly individuals who participated in health education groups in a Basic Unit in the Brazilian city of Porto Alegre (RS).

\section{METHOD}

This qualitative descriptive study was conducted in the IAPI Basic Health Unit, located in the northwestern district of the city of Porto Alegre (RS, Brazil), which in 2010, contained the second largest proportion of elderly individuals among all districts in the municipality. ${ }^{16}$ During the period when the investigation was conducted, there were approximately five thousand elderly individuals registered with this Basic Health Unit. The population of the northwestern region exhibits heterogeneous socio-economic conditions. The region contains neighborhoods with advanced infrastructure as well as areas of great socioeconomic vulnerability. ${ }^{17}$

The participants of the present study were linked to one of the three health education groups in the unit in question, which welcome elderly individuals: the Elderly Group; the Climacteric Group and the "Hiperdia" (blood pressure and diabetes) Group. The following inclusion criteria were used: individuals must be 60 years of age or older; and must live in an area served by the unit. The following exclusion criteria were used: individuals who had been hospitalized or were travelling during the data collection period; and those who were no longer a member of the group at the time of the interviews. The number of participants was intentionally defined. A sample of up to 30 people is considered adequate for qualitative studies ${ }^{18}$ and, to fulfil this criteria, the authors of the present study opted to interview ten elderly individuals from each of the three groups studied, totaling 30 participants.

Once in possession of the list of group participants that satisfied the eligibility criteria, contact was made by telephone. After this stage, ten individuals were excluded as they did not live in the coverage area, four were excluded for not participating in the group, three were excluded as they were under 60 years of age and two were excluded as they were travelling during the data collection period. Six other people did not agree to participate in the research. Interviews were scheduled with those that expressed an interest in participating. These were conducted between July and December of 2009, until arriving at the previously established number of participants. The interviews were carried out in a room in the Basic Health Unit by one of the research team. They were recorded and later transcribed. The present study used the first open question on the instrument 
applied in the Canadian study: "What does healthy aging mean to you?" Sociodemographic data were also gathered (gender, age and education).

Thematic analysis was used to analyze the data, with the support of Qualitative Solutions Research NVivo (QSR NVivo) software (Version 2.0). The thematic analysis contained the following stages: pre-analysis; exploration of the material; treatment of the results and interpretation of the material. ${ }^{19}$ During this analysis, the researchers read the interviews and categorized them. The final themes and categories were obtained based on a consensus among the research team.

The complete project received approval from the Research Ethics Committee of the Universidade Federal do Rio Grande do Sul (process no. 2007819/2008) and the Prefeitura de Porto Alegre ("Porto Alegre City Council") (process no. 001.029435.08.0/2008). All of the participants signed a free and informed consent form. The principles of autonomy, justice, nonmaleficence and beneficence were respected, in accordance with the Research Ethics Code of the Conselho Nacional de Saúde ("National Health Council"). ${ }^{20}$ The anonymity of the participants was guaranteed by the use of initials alongside their statements.

\section{RESULTS}

The participants were mostly female (90\%) and were aged between 62 and 82 years, with a mean age of 73 years. The educational level of the participants ranged from three to 17 years of study, with a mean of seven years.

Upon analysis of the interviewee responses, it was noted that the term healthy aging had several different meanings. Based on these statements, 12 categories were established and are presented below. Notably, during the analysis of the statements, their opinions were grouped into different categories. In other words, the empirical categories were not mutually exclusive.
Adopting healthy behavior

This category grouped together the answers provided by 18 elderly individuals who felt that healthy aging meant adopting healthy behavior, such as practicing physical activity, ensuring adequate nourishment, not smoking or drinking, maintaining good sleeping habits and resting.

[...] healthy means a good diet. (Elderly individual 8)

I think it's very good, because you take care of yourself. [...] You are not sedentary, I think that's it. [...] You take care of your personal bygiene as well. That's it. (Elderly individual 10)

It means going to bed early and getting up early, doesn't it? Sleeping well so you are ready for everything [...]. Not drinking too. Since I never smoked, I never drank. I am now 82 years old and I intend to live for a while yet. (Elderly Individual 18)

Participating in physical activity meant healthy aging and was also cited as a form of treatment and an opportunity to socialize:

It helps because we see other people, we have contact with them in the street [...] for exercise, for health, and we get to know each other, don't we? (Elderly individual 15)

\section{Having a social network and social support}

The category having a social network and support emerged in the answers of 14 of the interviewees, for whom healthy aging meant maintaining a social network, participating in a group of elderly individuals, maintaining networks of family and friends and having emotional support.

Maintaining a social network was common in the statements, referring to the network itself as a fundamental aspect of healthy aging:

It's an active social life isn't it? Social, active, being a part of everything, going on trips, visits, staying with the family. It's healthy aging. When we just stay in the house, we become isolated from everything. That's not a bealthy life, is it? (Elderly individual 16) 
A network of family and friends was highlighted in the statements as representing healthy aging.

That's it, I think, contact with your children as well, the affection and friendship of your children. [...] That's bealthy for an old person isn't it? [...] That's a good life. $V$ isiting a friend, having a friend's phone number. I think that's healthy, that's health. (Elderly individual 10)

Participation in groups, with the formation of a network of friends through familiarity and the opportunities for leisure provided, was also mentioned in the responses. The group was highlighted as an opportunity to learn and exchange knowledge with other elderly individuals and health professionals.

We are all together, all of our old friends. So you feel good because there [in the group] we go for walks, and the nurses do exercises with us. [...] You participate, you take your mind off things. [...] Together with your colleagues. (Elderly individual 4)

Emotional support was also associated with healthy aging. This meant more than simply being part of a network. It referred to the support that this network offers:

I think there is nothing sadder than somebody growing old alone. [...] We have what we need, don't we? Company, love, affection, that's important. [...] It's very sad to see people abandoned. They don't even have their children, do they? (Elderly individual 7)

\section{Staying active}

Statements from 12 interviewees were compiled to form this category. For them, healthy aging meant staying active through activities like trips, manual work, domestic tasks and readings:

Having something to do. In my case, for example, I do a lot of crochet, knitting and painting. [...] Keep moving, have something to do, or go to the supermarket or the shops. (Elderly individual 5)
A number of interviewees mentioned that staying active represented healthy aging as it is a form of maintaining their mental health:

Keeping your mind busy. [...] If I have nothing to do, I get irritable. (Elderly individual 10)

Having your health

For 11 elderly individuals, healthy aging meant having their health:

First and foremost, it means having your health. (Elderly individual 8)

When the answer "having your health" was given, the elderly individuals were questioned about what they thought "being healthy" meant. For some, health was understood as the absence of disease and/or pain. Others associated health with preventive attitudes (medical check-ups, examinations and vaccinations) and the adoption of healthy behavior (careful eating and physical exercise). Health was also understood as having the independence to perform activities of daily living.

\section{Being independent and autonomous}

For ten of the interviewees, healthy aging meant being independent. They emphasized the importance of remaining independent in relation to the performance of personal activities, doing things they like and being able to care for others. Other statements highlighted the importance of prevention in the maintenance of independence and autonomy:

Being able to move about. [...] Being able to communicate with people, to come and go as you please, I think that's bealthy aging. (Elderly individual 23)

Prepare for old age. [...] I got somebody to put a very low tap in the shower, so I wouldn't have to get water from outside and carry it when I cleaned the bathroom. (Elderly individual 27) 
One elderly individual associated independence with autonomy:

You need a clear head to know how to move, walk. [...] If you start to depend on other people, I think that's awful, very sad. [...] You need somebody of course, but not for everything, as if we were ill. (Elderly individual 8)

\section{Having positive feelings}

Having positive feelings emerged among the meanings for healthy aging according to ten of the interviewees. Positive feelings were associated with internal aspects, such as motivation and personal emotions, and external aspects, which are established by being part of a group:

Being calm and happy. (Elderly individual 25)

It's trying to live better, isn't it? You stay where you feel better. I felt better in the group, so that was very good for me. (Elderly individual 4)

The participants also stated, although less frequently, that healthy aging meant "having a faith/religion", "going to the doctor/following medical guidance", "the absence of illnesses", "aging as something negative", "having quality of life" and "taking care of your appearance".

\section{DISCUSSION}

As previously mentioned, when questioned about the significance of healthy aging, the elderly individuals provided a range of different answers. This shows the importance of understanding the focus of each individual in terms of the topic of the study, given that the aging process occurs in different ways and is influenced by lifestyles, socioeconomic conditions, the environment, health and heredity, among other things. ${ }^{21}$ Furthermore, in most cases, one individual cited multiple meanings for the expression, which underlines the existence of various aspects that can be correlated with healthy aging. These aspects are discussed in the categories created based on the statements.

Studies in which the authors used the terms active aging, healthy aging or successful aging are addressed in this discussion. Although these expressions represent different theoretical bases, they were approximated in order to expand the discussion of the theme in question, bearing in mind the low number of empirical studies addressing this subject. In addition, studies of aging and health were also used. ${ }^{13,14}$

Concerning the category adopting healthy behavior, careful nourishment and physical exercise are results that contradict the findings of other qualitative studies that sought to understand the definition of healthy aging for an elderly population in Minas Gerais, as well as conceptions regarding the health process, illness and preventive measures among the elderly in Rio Grande do Sul. In these studies and in the present study, the importance of avoiding risk factors, concern for self-care and personal hygiene were all mentioned in the statements. ${ }^{14,15}$ The correlation between health, active aging and physical activity was also mentioned in a study conducted in Paraíba, in which the authors analyzed the social responses of elderly individuals in relation to active aging. ${ }^{11}$ This category was the most common meaning of healthy aging due to the fact that the participants participated in a health education group containing a multiprofessional team (nurse, doctor, nutritionist and social assistant), who addressed these issues in the group.

Having a social network and support was a common response during the interviews. In the present study, a social network is understood to be a web of relationships that binds individuals who have some connection, enabling support to occur through these bonds. ${ }^{22}$ The existence of these social networks is extremely important to an active elderly individual as they lead to protection and prevent stressful situations associated with the aging process. This is perhaps what healthy aging means 
to the elderly. ${ }^{23}$ A quantitative study conducted in the metropolitan region of Porto Alegre (RS) found a correlation between elderly individuals who exhibited successful aging (determined by the highest quality of life scores) and the existence of inter-personal relationships. ${ }^{24}$ Another study ${ }^{15}$ identified family structure as a determining factor of healthy aging. Having a social network and support may have been commonly mentioned by the interviewees due to the fact that they have an extended social network, which includes the other participants of educational groups, as well as family members. In a previous study ${ }^{6}$ of elderly individuals who participated in community groups and centers for the third age, the interviewees stated that one of the main reasons for frequenting these groups was to socialize and interact with other people. The same individuals used these groups as a place to share their feelings and forge new friendships. They believe that the groups promote social wellbeing and improve their will to live.

As well as family members, another important social network that emerged from the statements was the network of friends. It is important to distinguish family networks, which are involuntary and in some ways "obligatory" from friend networks, which are selected voluntarily based on desirable attributes and common aspects. ${ }^{23-25}$ While the family network involves rights and duties attributed by society to each individual, and is associated with permanent long-term assistance, friendships are more closely associated with symbolic exchanges and emotional satisfaction. ${ }^{25}$ These two types of relationship can involve affectionate exchanges and wellbeing. This may be why they were part of the meaning of healthy aging, according to the elderly individuals assessed.

In the present study, the elderly group was one of the most commonly mentioned social networks in the definition of healthy aging. It is believed that these groups enable the elderly to interact with other people of the same age group, as well as providing a place to chat and exchange ideas with other participants. In a previous study conducted in the municipality of Ijuí (RS), ${ }^{26}$ the authors reported that the possibility of personal interaction, sharing knowledge and happiness, and the renewed satisfaction of being with other people were the main reasons why elderly individuals frequented these social groups. Similar results were recorded in the present study, thereby confirming the high value attributed to these groups by the elderly. The chance to talk with health professionals is also important. According to the Ministério da Saúde ("Ministry of Health"), group work, especially in basic healthcare services, seeks to improve the link between the health team and the elderly, serving as a health education tool. ${ }^{27}$ It is believed that healthcare professionals who work in the basic healthcare environment perform the role of facilitators in health education groups. It is important that they are aware of the needs of the participants, such as information about the health-disease process, as well as other queries that may arise. Thus, it is possible to create and implement effective health promotion strategies for this age group.

Emotional support, which involves expressions of love and affection and has been correlated with positive outcomes in the life of the elderly, such as health and wellbeing, ${ }^{23}$ also represented healthy aging for the interviewees. It was notable that the elderly participants in the present study valued emotional support more than instrumental and economic support. It is believed that this result is due to the fact that these elderly individuals are physically and financially independent and as such, emotional support is more relevant to their needs.

Concerning the category keeping active, it was notable that the elderly individuals associated it with activities that kept them busy or provided them with a leisure opportunity. Therefore, for the participants, keeping active involves more individual aspects than collective aspects - the continuous participation in society cited in the policy of active aging. ${ }^{1}$ 
The results obtained in the category keeping active highlight the importance of activities that allow the elderly to remain socially active, thereby reducing the impact of the changes that occur in this phase of life and decreasing the negative effects of these changes on their lives. Participation in health education groups can provide the elderly with an opportunity to socialize and take part in social activities, thereby giving their lives goals and objectives. Similar results have been reported in previous studies, in which keeping active and leisure activities were also correlated with healthy, successful and active aging. ${ }^{10-12,15}$ In old age, people tend to confront changes and losses in their role in society, even in retirement. ${ }^{26}$

Concerning the category having your health, statements from the elderly participants that associated health with the absence of disease and/ or pain, nourishment and physical activity can be classified as concepts that are grounded in "the biological dimension of health". ${ }^{14}$ The perspective of health linked to the performance of examinations shows that health is still associated with a medicalcurative model. According to the authors, these elderly individuals have a strong dependence on medical check-ups and follow medical guidance in their daily lives. ${ }^{14}$ Also in this category, several interviewees stated that health meant having the independence to perform activities of daily living. It is known that maintaining functional capacity is an important indicator of health in the elderly population, who often base their health-related perceptions on independence while performing activities of daily living, even if they suffer from a chronic illness. ${ }^{12}$ In this category, the responses differed from those reported in an earlier study, in which the absence of disease was not the only health indicator during old age, based on the conceptions of the elderly individuals themselves. ${ }^{13}$

Being independent and autonomous was another category that arose among the meanings of healthy aging. The concepts of autonomy and independence are interconnected and inter-dependent, in that the former can be defined as the capacity to act and make decisions, whereas the latter can be defined as being able to execute your tasks without help from another person. ${ }^{27}$ In this category, the participants highlighted instrumental activities, the autonomy of the individual and the importance of prevention in maintaining both. An earlier study ${ }^{13}$ also reported the importance of maintaining independence, autonomy and the capacity to do what you want (travel and get around) to healthy aging. It is notable that educational groups provide these conditions and actively encourage them. Perhaps, this is why they represented healthy aging for the elderly individuals interviewed.

In the category having positive feelings, the participants mentioned that healthy aging means having a calm lifestyle, feeling good and not worrying about things. This association with positive feelings was also reported in earlier studies, in which the absence of problems and a happy, harmonious life (psychological wellbeing) were among the aspects that the interviewees correlated with healthy and successful aging. ${ }^{10-15} \mathrm{In}$ this category, positive feelings were also correlated with socializing in the elderly group, contrary to an earlier study, ${ }^{26}$ which demonstrated how the group favors the recovery of pleasure, satisfaction and joy when with other people.

A previous study ${ }^{11}$ was carried out with elderly individuals in a Family Health Unit, addressing the social representations of active aging. Four classes of responses were recorded in the statements made by the elderly individuals assessed: general aspects related to the life of the individual; leisure; domestic activities and physical activities. When compared with the categories obtained in the present study, it is notable that the adoption of healthy behavior (not restricted to practicing physical activities) and having a social network and support were mentioned in the present study, unlike the abovementioned study. These differences may have been affected by the fact that the interviewees participated in health education groups, where this 
type of behavior is encouraged and a social network has been established with health professionals and other elderly individuals. Furthermore, similar to the present study, the authors highlighted that active aging was connected to independence and autonomy. ${ }^{11}$ It is understood that the use of the expression healthy aging in the present study favored the understanding of the participants, allowing them to provide more extensive meanings than were provided for active aging.

Collective issues, such as continuous participation in the community and its decisions, were not identified in the statements of the elderly individuals, who looked at healthy aging from a more individual perspective. This may have occurred as a result of the terminology used in the study, since "healthy aging" mainly refers to issues associated with healthcare. It may also have been due to the fact that the focus of the groups was personal care and not the possibility of changing situations. The different definitions attributed by the elderly participants in the present study reinforced the importance of understanding distinct perspectives when dealing with this population, in order to provide them with more specific resources, focusing on their needs.

It is important to stress that the individuals who participated in the present study were members of health education groups, which may have influenced the results, thereby representing a limitation of this investigation. Future studies should seek to understand the meaning of healthy aging among elderly individuals who are not linked to group activities. This will improve healthcare services for all and enable comparisons with the results obtained in other studies, including those reported herein.

\section{FINAL CONSIDERATIONS}

In the present study, 12 categories emerged from the statements of the elderly when discussing the meaning of healthy aging. This demonstrates that aging healthily can be perceived differently by each individual and a single elderly person may address several issues that are relevant in this process. Adopting healthy behavior, having a social network and support and keeping active were the most common meanings cited by the participants.

Concerning the category adopting bealthy behavior, it is possible to conclude that the elderly considered practicing physical activity, careful eating, good personal hygiene, not drinking or smoking and good sleeping/resting habits as important factors in healthy aging.

In the category having a social network and support, the maintenance of a social network, participation in the elderly groups, the family network, friendships and emotional support were addressed by the elderly in their statements on healthy aging.

In the category keeping active, the participants correlated healthy aging with the importance of performing activities that keep them busy, such as manual and domestic tasks, readings and trips.

The present study showed that elderly individuals understand the concept of healthy aging, given that the participants assessed attributed a wide range of meanings to the theme. These meanings were not restricted to the absence of illness or disabilities. They also addressed issues that are relevant to the healthcare of the elderly population. Since the meaning of healthy aging for the elderly only considers personal issues that are related to their own health, it is important to promote health and encourage the empowerment of this group, as well as their capacity to see themselves as citizens. In so doing, they will become more active and involved in decisions concerning their health and the community. Thus, health professionals who work in basic healthcare services must play a fundamental role in health promotion activities for the elderly. 


\section{REFERENCES}

1. Organização Mundial da Saúde. Envelhecimento ativo: uma política de saúde. Brasília; DF:

Organização Pan-Americana de Saúde, 2005.

2. Vitorino SS, Miranda MLJ, Witter C. Educação e envelhecimento bem sucedido: reflexões sobre saúde e autocuidado. Rev Kairós 2012;15(3):29-42.

3. Bartlett H, Peel N. Healthy Ageing in the community. In: Andrews GF, Phillips DR. Ageing and place: perspectives, policy, practice. New York: Routledge; 2005. p. 98-109.

4. Peel N, Bartlett $\mathrm{H}, \mathrm{McCl}$ re R. Healthy ageing: how is it defined and measured? Aust J Ageing 2004;23(3):115-9.

5. Gardner PJ. Envelhecimento saudável: uma revisão das pesquisas em Língua Inglesa. Movimento 2006;12(2):69-92.

6. Wichmann FMA, Couto AN, Areosa SVC, Montanes MCM. Grupos de convivência como suporte ao idoso na melhoria da saúde. Rev Bras Geriatr Gerontol 2013;16(4):821-32.

7. Both JE, Leite MT, Hildebrandt LM, Pilati ACL, Stamm B, Jantsch LB. Grupos de convivência: uma estratégia de inserção do idoso na sociedade. Rev Contexto Saúde 2011;10(20):995-8.

8. Almeida EA, Madeira GD, Arantes PMM, Alencar MA. Comparação da qualidade de vida entre idosos que participam e idosos que não participam de grupos de convivência na cidade de Itabira-MG. Rev Bras Geriatr Gerontol 2010;13(3):435-44.

9. Paskulin LMG, Aires M, Valer DB, Morais EP, Freitas IBA. Adaptação de um instrumento que avalia alfabetização em saúde das pessoas idosas. Acta Paul Enferm 2011;24(2):271-7.

10. Vilela ABA, Carvalho PAL, Araújo RT.

Envelhecimento bem-sucedido: representação de idosos. Rev Saúde.Com [Internet] 2006 [acesso em 9 nov. 2009];2(2):101-14. Disponível em: http://www. uesb.br/revista/rsc/v2/v2n2a2.pdf

11. Ferreira OGL, Maciel SC, Silva AO, Santos WS, Moreira MASP. O envelhecimento ativo sob o olhar de idosos funcionalmente independentes. Rev Esc Enferm USP 2010;44(4):1065-9.

12. Ferreira OGL, Maciel SC, Costa SMG, Silva AO, Moreira MASP. Envelhecimento ativo e sua relação com a independência funcional. Texto \& Contexto Enferm 2012;21(3):513-8.
13. Teixeira MCTV, Schulze CMN, Camargo BV. Representações sociais sobre a saúde na velhice: um diagnóstico psicossocial na Rede Básica de Saúde. Estud Psicol [Internet] 2002 [acesso em 10 out. 2009];7(2):351-9. Disponível em: http://www.scielo. br/pdf/epsic/v7n2/a16v07n2.pdf

14. Vilarino MAM, Lopes MJM. Envelhecimento e saúde nas palavras de idosos de Porto Alegre. Estud Interdiscip Envelhec 2008;13(1): 63-77.

15. Cupertino APFB, Rosa FHM, Ribeiro PCC. Definição de envelhecimento saudável na perspectiva de indivíduos idosos. Psicol Reflex Crit [Internet] 2007 [acesso em 10 out 2009];20(1):81-6. Disponível em: http://www.scielo.br/pdf/prc/v20n1/a11v20n1.pdf

16. Observa POA - Observatório da cidade de Porto Alegre [Internet]. Porto Alegre: Prefeitura de Porto Alegre; 2010. Indicadores das regiões e bairros; 2010 [acesso em 26 set 2015];[aproximadamente 2 telas]. Disponível em: http://portoalegreemanalise. procempa.com.br/?regiao=3_10_150

17. Paskulin LMG, Vianna LAC. Perfil sociodemográfico e condições de saúde auto-referidas de idosos de Porto Alegre. Rev Saúde Pública 2007;41(5):757-68.

18. Polit DF, Beck CT, Hungler BP. Fundamentos de pesquisa em enfermagem: métodos, avaliação e utilização. $5^{a}$ ed. Porto Alegre: Artmed; 2004.

19. Minayo MCS. O desafio do conhecimento: pesquisa qualitativa em saúde. $8^{a}$ ed. São Paulo: Hucitec; 2008.

20. Brasil. Resolução no 466, de 12 de dezembro de 2012. Aprova diretrizes e normas regulamentadoras de pesquisas envolvendo seres humanos. Brasília: Conselho Nacional de Saúde; 2012 [acesso em 26 set 2015]. Disponível em: http://conselho.saude.gov.br/ resolucoes/2012/Reso466.pdf

21. Guimaraes ML, Souza MCMR, Azevedo RS, Paulucci TD. O cuidado ao idoso em saúde coletiva. In: Souza MCMR, Horta NC. Enfermagem em Saúde Coletiva: teoria e prática. Rio de Janeiro: Guanabara; 2012. p. 300 -13.

22. Pedro ICS, Rocha SMM, Nascimento LC. Apoio e rede social em enfermagem familiar: revendo conceitos. Rev Latinoam Enferm 2008; 16(2):324-7.

23. Paúl C. Envelhecimento activo e redes de suporte social. Sociologia 2005;15:275-87.

24. Moraes JFD, Souza VBA. Factors associated with the successful aging of the socially-active elderly in the metropolitan region of Porto Alegre. Rev Bras Psiquiatr 2005;27(4):302-8. 
25. Erbolato RMPL. Relações sociais na velhice. In: Freitas EV, Py L, editores. Tratado de Geriatria e Gerontologia. Rio de Janeiro: Guanabara Koogan; 2011. p. 957-64.

26. Leite MT, Cappellari VT, Sonego J. Mudou, mudou tudo na minha vida: experiências de idosos em grupos de convivência no município de Ijuí/RS. Rev
Eletrônica Enferm [Internet] 2002 [acesso em 30 out. 2009]; 4(1):18-25. Disponível em: http://revistas.ufg. br/index.php/fen/article/view/746/811

27. Brasil. Ministério da Saúde, Secretaria de Atenção à Saúde, Departamento de Atenção Básica.

Envelhecimento e saúde da pessoa idosa. Brasília, DF: Ministério da Saúde; 2006.

Received: March 11, 2014

Revised: March 26, 2015

Accepted: July 20, 2015 